\title{
The Responsibilities and Behavioral Reactions of the Senior Management in Layoffs Events
}

\author{
Li-kun WEI \& Wei-zheng CHEN \\ Business School, Sichuan University, China
}

\begin{abstract}
As the decision makers and planners in downsizing, the senior management's roles and behavior are the key factors to the downsizing effectiveness. We collected 120 layoffs events from January 2001 to January 2013 in China, with multiple case studies based on content analysis. Research shows that senior management emerged 15 kind of behavior modes come down to 5 kind responsibilities just as: downsizing strategy, implementation, communication, organizational reputation and employee morale. The prominent problems were: the violation credibility behavior was obvious; lack of clear roles orientation and behavior standard, the actual behavior of the senior management deviated from job responsibilities; the understanding for strategic intention of downsizing was not clear, the senior management's strategic status and contribution in downsizing were not outstanding.
\end{abstract}

KEYWORD: Downsizing; Senior Management; Responsibilities; Behavioral Reactions; Chinese Company

\section{INTRODUCTION}

The absorption and exit of human resources is a selfregulatory mechanism of the organization to adapt to the external environment. When the competition intensifies, through redundancy to optimize the allocation of the human resources, can realize highly efficient organization structure, to maintain the creativity and adaptability. Downsizing as a kind of management changes, embody a concentrated reflection of senior management's rational or limited rational behavior. Therefore, the effectiveness of organizational downsizing depends largely on the role orientation and behavior of the top managers.

\section{RESPONSIBILITIES IN DOWNSIZING}

In the process, organization downsizing mainly involve the planners or principal, executive or agent, victims and survivors. The first two roles are usually regarded as the managers; the latter two are in the charge of managers. In the research of downsizing planning and implementation, western scholars tend to see the senior management as downsizing planers and facilitators. Sweeney (2011) considered that downsizing is essentially a balancing act: managing the legacy of the organization; Its reputation and its ongoing business performance; Managers should focus on five tasks in turn: (1) retention of corporate reputation; (2) manage communications; (3) manage the actual closure ; (4) manage investment in employees; (5)manage continuity of operations. Because downsizing will be led to negative effects on the organization and staff, enterprise top managers often face a greater risk management, therefore, in the process of downsizing need to undertake the following five management responsibilities:

\subsection{To choose the downsizing strategy}

Downsizing strategy is the overall plan and action program to organize the implementation of downsizing, is the important way of achieving an organization's strategic intent. Cameron (1994) through case studies for best downsizing practice, summed up the three application strategy: workforce reduction strategy, work redesign strategy, systemic strategy. Because the downsizing often lead to unemployment and reduced the employee's job security, since the $1980 \mathrm{~s}$, scholars have put forward the strategy of the alternative to layoffs, such as reducing opportunities for advancement, freeze on wages, job sharing and so on. In fact, the recessive layoffs and soft layoffs based on avoid labor laws and economic compensation were the reality show of alternative strategy. 


\subsection{To support the change, promote the downsizing implementation}

Downsizing as a way of resource optimization, usually break the existing rights relations, therefore face greater resistance to change. Top management is the enterprise's strategic decision makers and radical reformers. As "agents of change", they tend to take the downsizing as the transformation, strategic oriented, focus on efficiency of layoffs and the organization's financial performance indicators. As a result, once decided to implement downsizing, they must have a good reason and clear objectives for downsizing, through the planning, publicity and vision, decisive action, to achieve the business goals.

\subsection{To maintenance organization reputation}

On the research about the influence of downsizing to corporate social performance reputation showed: regardless of the success of layoffs and downsizing, the company's social performance reputation will be affected negative in different degree; between the high financial performance and social performance reputation, company managers are more willing to choose the former, and give up the latter (Zyglidopoulos,2004). Kammeyer Mueller and Hui Liao (2006) found that cuts labor will reduce the attraction of the job seekers, however, if the company provide employees with the aid of downsizing and adequate communication, employers attractive will fairly same as no to layoffs.

\subsection{To communicate efficiently}

Honest, open communication, frequent information communication can prevent gossip, when information is not sufficient, the employees will use their own assumptions and rumors to fill gaps, information and these assumptions or rumors are often based on the worst situation (Caudron,1996) . Dayou Cao and Shuming Zhao (2004) suggested that the internal and external communication are the most important and most complex management activities in the layoffs process, directly affect the employees' psychological state and organizational climate, therefore, in the practice of the layoffs, companies are often pay attention to the design of the communication project and the implementation of the communication activities, strive to scientific and reasonable, in order to reduce the negative effect of downsizing activities to a minimum.

\subsection{To restore morale}

Downsizing often threat to employee's job stability and break the management trust. When employees consider layoffs behavior invalid or injustice, their job security is reduced and lose confidence for future development. Survivors become risk averse, short- term compromises, conservative and loss the ability to innovate. Low morale also tends to spill over to other areas and activities in the corporation. Motivation generally is affected. Productivity tends to suffer and an overall climate of discontent takes over in the corporation. Other side effects seem to accompany the decline in morale. They include a sense of loss and alienation, a sense of chaos, and a strong sense of uncertainty. These are particularly unwelcome when they are found in middle managers, since they tend to serve as examples and to transfer their feelings to their subordinates. (Makawatsakul, 2003)

\section{RESEARCH METHODS}

Because downsizing often as the sensitive event, with the means of field research and interviews to obtain really and primary data is difficult. Therefore, this study limited the range of case studies for the following: take multiple case studies based on content analysis with "layoffs" events as the main line; To highlight the characteristics of the current practices of downsizing in China, the sampling time between January 2001 and January 2013; Case datum released by the official news reports and the source of every case is not less than three media. After collecting and sorting we get 120 cases of China's corporate downsizing practice.

With quantitative analysis of semantic content, the smallest unit of semantic analysis is sentences. To code according to common facts and theme presented by data itself. To ensure coding validity, this study invited three HR manager and three business management graduates to complete coding, the reliability coefficients of Holsti at the acceptable level of more than 0.80 . This study in-depth literature research laid a good theoretical basis for code design; coders had a better training, so to define coding had accurate understanding; encoding process in strict accordance with the procedures, to ensure the high content validity.

\section{RESEARCH FINDINGS}

In the study, the data about downsizing strategy appears $100 \%$ of 120 cases; the data about senior managers appear s $43.3 \%$.

This study invited coders to classify the behavioral reactions to job responsibilities. At first classified the contradictory behavior, such as: "recognize layoffs" and "deny layoffs", in this step four groups opposing behavior modes were found; secondly, classified the executive behavior according to the connotation and the function object of the senior management's responsibilities. 
The specific classification and characteristics as shown in table 1:

Table 1.the Behavior Modes and Classification of the Senior Management in Layoffs Event (unit: \%)

\begin{tabular}{llc}
\hline Responsibility & \multicolumn{1}{c}{ Behavior Mode } & Frequency \\
\hline Downsizing Strategy & Workforce reduction & 76.7 \\
& Work redesign & 54.2 \\
& Systemic strategy & 0.8 \\
& Alternative strategy & 34.2 \\
Implementation & Support layoffs & 19.2 \\
& Promote vision & 9.7 \\
& Against layoffs & 3.9 \\
Communication & Explain the layoffs & 21.2 \\
& Guilt apology & 13.4 \\
& Keep silent & 1.8 \\
Organizational & Denied the layoffs & 27.0 \\
Reputation & Inconsistent & 21.2 \\
& Admit that layoffs & 19.2 \\
Employee Morale & Promise not to layoffs & 7.6 \\
& Break a promise & 3.9 \\
\hline
\end{tabular}

\subsection{Downsizing strategy: Short-termism and instrumental, dominated by workforce reduction strategy}

From the quantity, the cases to take the workforce reduction strategy accounted for $76.7 \%$; use the work redesign strategy accounted for $54.2 \%$; only 1 case with systemic strategy and the cases used alternative strategies reached $34.2 \%$. This illustrates that Chinese companies' target of downsizing strategy tended to short-termism very significant.

From the content, Chinese enterprises not only tended to "seniority to zero" strategy to evade the risk of "labor contract law" implementation, but take to "disguised layoffs" strategy such as free overtime, pay cuts, knock off, take a vacation, retain the job but suspend the salary and so on.

From strategic position, although many companies frequently used function optimization strategy such as organization adjustment, department cancel, business restructuring. However, most enterprises chose the strategy passively and under the performance decline, the systemic strategy as for more strategic prospective but not popular.

\subsection{Downsizing Implementation: Most support and minority oppose}

About $19.2 \%$ of the cases, senior management publicly supported downsizing, such as claimed "the organization integration and optimization is the company's normal activity." (KINGDEE, 2011); 9.7\% cases executives promoted vision, such as " In order to practice Wal-Mart's mission 'save money for customers and make better life ', we must improve the efficiency further." (Wal-Mart,2012); but $3.9 \%$ of the cases executives opposed downsizing openly and against superior, such as CONNGAME.COM(2010) and Ku6 (2011) layoffs events, as a result was the resignation or dismissal.

\subsection{Communication: Explain the reason, guilt apology and keep quiet}

About $21.2 \%$ of the cases executives explained the rumor of downsizing, such as $\mathrm{Mr}$. Du, head of RIZHAO steel in the form of the letter to the all staff, explained the reason why the company "compression personnel". $13.4 \%$ of the cases executives expressed his guilt and regret, such as: "As the 'boss' 10 years ago, I still feel guilty for the company need to downsizing ", send series nearly 30 pieces weibo to respond to victims (Bubugao, 2011); "For every employees affected in the plan, we will give the care and respect." (Lenovo, 2009).But there are some executives kept silent declined to comment when they faced the employees and the media questioned.

\subsection{Organizational reputation: Deny or recognize, duplicity, inconsistent}

Although it was showed hard evidence to clarify that enterprise had taken downsizing actions, but $27 \%$ of the cases executives denied the rumor, or regarded it as a normal personnel adjustment or not the economic layoffs or not the initiative layoffs; $19.2 \%$ of the cases executives confirmed the rumor, such as " the news of downsizing has been released in the first quarter of this year, there is no need too much attention" (Utstarcom,2005); 21.2\% of the cases executives tend to duplicity, inconsistent, denied the layoffs but confirmed layoffs in explanation. Such as: in the 2009, Lenovo company claimed that no downsizing plan in China, on the contrary, would increased the staffing level, but afterwards, the executives said: "it's difficult to make this decision, but this is the necessary measures response to the global economic downturn."

\subsection{Employee morale: Promise not to layoffs and break promise}

About $7.6 \%$ of the cases executives publicly promised not to layoffs, such as "in the future, no matter how the market changes, SOHO China won't be so massive layoffs" (SOHOChina, 2009); however, $3.9 \%$ of the cases executives had violated promise, such as: promised not to layoffs, the letter said to cut (Alcatel China, 2002).

\section{PROBLEM DISCUSSION}

Further research shows that the senior management 
of Chinese enterprise had certain crisis public relations consciousness in dealing with layoffs event, but lack of clear responsibility orientation and moral standards, the prominent problem and causes were:

\subsection{Lack of integrity and professional reputation supervision mechanism, tend to be opportunistic}

In some layoffs events, the Chinese enterprise top managers violated business integrity more or less, such as: lying, denied layoffs, break promise etc...When they explained the legitimacy and rationality of downsizing, their legal consciousness and the business ethics had been questioned. Influenced by planned economy, the Chinese can't completely adapt to the market-oriented employment mechanism, along with the severe employment pressure and imperfect labor laws and social security mechanism, result to the relatively low acceptance for layoffs in China society. As the agents of organizational reformers, Chinese executives lack of understanding of the strategic value and the effect of downsizing, combined with the missing of the business reputation and professional reputation evaluation systems. Led to the legal accomplishment and organizational justice consciousness of the Chinese top manager were insufficiency and like to be opportunistic.

\subsection{Lack reasonable boundary of the layoffs, manager's behavior deviated from job responsibility}

Compared with western developed countries, the layoffs for most Chinese enterprises is still a new thing. Although a series of legitimacy standards to layoffs formulated by China government, which specifies the "base-line" of layoffs behavior. But the ethical standards in downsizing management could not be defined at macro level, only to advocate the enterprise social responsibility and the civic consciousness to promote the "rationality" of downsizing managers. This would give chance to violate and misconduct in downsizing. As a result, the actual behavior of the top managers deviated from responsibility requirements. Such as: the top managers should be layoff planner and strategy advocates, but against company layoffs publicly; Facing the outside hearsay, executives took an avoidance approach, declined to comment, even blocked information. Such behavior reactions led to continuous fermentation of the layoffs event and loss of public trust.

\subsection{Lack understanding of the systematic in downsizing management, the subjective arbitrariness of the managers is too high}

Although downsizing management is the common phenomenon of contemporary economic society. But Chinese managers often regard the layoffs as an exception of emergencies. Short of research and plan in advance, lack of a unified specification in process, lack of crisis public relations capacity after the event. The standards and process in downsizing management were not defined strictly, the autonomy of managers tend to be amplified, encouraged the unspoken rules and subjectivity. In addition to, downsizing often accompanied the high-level personnel changes, result to power vacuum and even high-level confrontation. So lead to management missing or poor regulation and weakened the systemic and collaborative in downsizing management. This also confirmed that Chinese manager's strategy skill is insufficient relatively and need to improve urgently.

\section{CONCLUSION}

This study provides an empirical basis to improve the effectiveness of the downsizing management, provide theoretical basis to promote the downsizing standardization. Due to the case study with the aid of second-hand data, many hidden layoffs behavior made has not been involved. The future research need collect data through on-the-spot investigation and interview method in the future study, in order to make up for the limitation of this study.

\section{REFERENCES}

[1] Cameron, K.S...1994. Strategies for successful Organizational Downsizing. Human Resource Management, Vol. 33 No.2:189-211.

[2] Cao Da-you, Zhao Shu-ming. 2004. The analysis of the management behavior in transformational downsizing. Foreign economic and management, 26(5): 17-20.

[3] Caudron, S... 1996. Teach downsizing survivors how to thrive .Personnel Journal, 75 (1):38-41.

[4] Kammeyer-Mueller J., Hui Liao. 2006. Job-seeker attraction: examining job seekers' reactions to firm workforce- reduction policies. Human resource management, winter 45(4):585-603.

[5] Makawatsakul, N. \& Kleiner, B. H... 2003. The effect of downsizing on morale and attrition. Management Research News, 26(2/3/4):52 - 62 .

[6] Sweeney M. 2011.Managing Downsizing: Key Considerations.

http://www.som.cranfield.ac.uk/som/p16640/ThinkCranfield/2011/August-2011/Managing-Downsizing.

[7] Zyglidopoulos, S.C.. 2004. The impact of downsizing on the corporate reputation for social performance. Journal of Public Affairs, 4: 11-25. 